\title{
Doenças que ocorrem nas criações de galinhas caipiras em duas comunidades quilombolas no Recôncavo da Bahia
}

\section{Diseases that occur in cultivation of redneck poultry in two quilombola communities in Recôncavo da Bahia}

\section{Rita Santos NASCIMENTO'; Andreia Santos do NASCIMENTO²; Tatiana Cristina da ROCHA ${ }^{3}$}

\begin{abstract}
${ }^{1}$ Autor para correspondência. Tecnóloga em Agroecologia, Universidade Federal do Recôncavo da Bahia, Cruz das Almas, Bahia, 44380-000, Brasil. E-mail: asnrita@yahoo.com.br

${ }^{2}$ Doutora em Ciências (Entomologia Agrícola), Universidade Federal do Recôncavo da Bahia, Cruz das Almas, Bahia, 44380000, Brasil. E-mail: asndea@gmail.com

${ }^{3}$ Docente do Centro de Ciências Agrárias, Ambientais e Biológicas, Universidade Federal do Recôncavo da Bahia, Cruz das Almas, Bahia, 44380-000, Brasil. E-mail: tatianarocha@ufrb.edu.br
\end{abstract}

Recebido em: 15-01-2020; Aceito em: 09-06-2020

\begin{abstract}
Resumo
Muitas doenças podem acometer as aves caipiras em criações domésticas (avicultura familiar) comprometendo a produtividade das mesmas e, em alguns casos, reduzindo o número de indivíduos do plantel. Dessa forma, as doenças das aves podem comprometer a renda do avicultor familiar que realiza esta atividade como fonte alternativa de renda, em muitos casos, bem como para subsistência. Assim, neste estudo tem-se como objetivo catalogar os tipos de doenças que ocorrem em criações domésticas de galinha caipira em duas comunidades quilombolas no Recôncavo da Bahia. Para aquisição de informações sobre a ocorrência de doenças, sintomas apresentados e tratamento adotado para o controle das enfermidades, foi aplicado um questionário composto por 20 questões para os criadores de galinha caipira de duas comunidades quilombolas localizadas no município de Cruz das Almas, Bahia, situado no Território de Identidade do Recôncavo da Bahia. A análise dos dados revelou que mais de $85 \%$ dos criadores de galinhas caipiras nas comunidades quilombolas visitadas no Recôncavo da Bahia são do sexo feminino. A maioria dos criadores (78,95\%) comercializam os produtos da avicultura, principalmente ovos e aves adultas. Os criadores relataram onze tipos de doenças que acometem as aves. A coriza infeciosa (gôgo) foi a principal doença registrada na criação de galinhas caipiras no local de estudo. O controle das doenças das aves nas comunidades é preventivo e, na maioria dos casos, as aves são tratadas com uso de medicamentos alternativos baseados no conhecimento popular.
\end{abstract}

Palavras-chave adicionais: aves; avicultura familiar; patógeno; sanidade avícola.

\begin{abstract}
Many diseases can affect the redneck poultry in domestic cultivation (family poultry) compromising the productivity of the poultry and in some cases reducing the number of individuals in the flock. Poultry diseases can compromise the income of the family poultry farmer who performs this activity as a alternative source of income, in many cases, as well as for subsistence. Thus, this study aims to catalog the types of diseases that occur in domestic cultivation of free-range chicken in two quilombola communities in Recôncavo da Bahia. In order to acquire information about the occurrence of diseases, type of symptoms and treatment adopted for disease control, a questionnaire consisting of 20 questions was applied to free-range hen breeders from two quilombola communities located in Cruz das Almas, Bahia, Brazil, located in the Identity Territory of Recôncavo da Bahia. Data analysis revealed that over $85 \%$ of the free-range chicken farmers in the quilombola communities visited in Recôncavo da Bahia are female sex. Most breeders (78.95\%) market poultry products, mainly eggs and adult poultry. The breeders reported eleven types of diseases that affect the birds. Infectious coryza ("gôgo") was the main disease recorded in the rearing of free-range chickens in the studied site. The control of bird diseases in communities is preventive and in most cases birds are treated using alternative medicines based on popular knowledge.
\end{abstract}

Additional keywords: family poultry; pathogen; poultry, poultry health.

\section{Introdução}

A avicultura familiar tem características peculiares, principalmente relacionadas ao tamanho das criações e na maioria dos casos ao melhor aproveitamento dos recursos da propriedade e menor dependência de insumos externos (FAO, 2014; Delgado \&
Bergamasco, 2017). A grande maioria dos criadores de aves em pequena escala opta pela criação de galinhas caipiras (Gallus gallus domesticus L.), pois estas aves introduzidas no Brasil no período do descobrimento são mais resistentes a doenças e mais facilmente adaptadas a diferentes condições climáticas (Van Eekeren et al., 2006; Embrapa, 2007; Sankhyan et al., 
2013). Embora mais resistentes, as aves caipiras também podem ser acometidas por doenças diversas, bem como infestação com parasitas (Embrapa, 2007; Quinzeiro Neto et al., 2017).

Um dos maiores problemas dos criadores de aves domésticas está relacionado ao manejo e sanidade (bem-estar, boa saúde e higiene) do seu plantel (Rennó et al., 2008, Albuquerque et al., 1998). Embora sejam relatados avanços tecnológicos com uso de equipamentos e sistemas monitoradores no setor avícola, o que contribui positivamente para aumento da produção e tratamento de doenças, muitas destas tecnologias não é apropriada para atender as necessidades do produtor familiar, devido ao custo elevado (Alders et al., 2018; Schmidt \& Silva, 2018). Dessa forma, medidas de controle preventivas com uso de produtos alternativos como limão, alho e vinagre são adotadas com maior frequência nas criações de aves caipiras em pequena escala (Sales, 2015).

Uma gestão adequada da sanidade avícola é um componente importante da produção de aves. Os agentes causadores de doenças infecciosas se disseminam rapidamente acometendo grande parte dos animais ou todo o plantel, principalmente quando existe alta densidade na lotação de aves nas instalações mesmo em criações domésticas (Barbosa et al., 2008; Poultryhub, 2019).

Dentre os animais escolhidos para criação em comunidades quilombolas destaca-se a criação de bovinos e aves, sendo a galinha caipira a mais frequente (Embrapa, 2007; Machado, 2016; Machado \& Mera, 2016). Para a maioria dos criadores, as aves representam um complemento na fonte alimentar, recurso proteico, bem como uma fonte alternativa de renda. Na maioria dos casos, avicultura é uma atividade exercida para subsistência da família (Cruz et al., 2013; Nogueira \& Jesus, 2013; Heck, 2016; Alders et al., 2018). Assim, a perda de animais acometidos por doenças não é desejável, pois consequentemente ocorre uma redução da produtividade, o que pode comprometer a alimentação e orçamento familiar.

Nas comunidades quilombolas a criação de galinhas caipiras para consumo como fonte de alimento proteico e venda de produtos avícolas (ovos, pintinhos e carne) para complementação do orçamento familiar é frequente (Santos \& Garavello, 2016). No entanto, inventários relacionados às doenças que comumente acometem as aves nesses ambientes são escassos na literatura. Nesse sentido, o presente estudo pode contribuir com informações a respeito das doenças que ocorrem na avicultura familiar desenvolvida em duas comunidades quilombolas no Território de Identidade do Recôncavo da Bahia.

Dessa forma, este estudo foi desenvolvido com o objetivo de catalogar os tipos de doenças que ocorrem em criações domésticas de galinha caipira em duas comunidades quilombolas do Recôncavo da Bahia. Adicionalmente, registar o perfil dos criadores de galinha caipira, o tipo de tratamento adotado para controle de doenças de aves pelos criadores e o tipo de manejo adotado na criação de galinha caipira nas duas comunidades.

\section{Material e métodos}

Para aquisição de informações sobre a ocorrência de doenças nas aves, tipo de sintomas e tratamento adotado para o controle de doenças, foi aplicado um questionário composto por 20 questões para criadores de galinhas caipiras de duas comunidades quilombolas (Comunidade da Baixa da Linha e Comunidade da Vila Guaxinim) localizadas no município de Cruz das Almas (12³9'10"S; 3907'19"W), situado no Território de Identidade do Recôncavo da Bahia. A distância geográfica entre as comunidades é de aproximadamente $1 \mathrm{~km}$.

De acordo com informações da ClimateDate.Org o clima do município é tropical, com uma pluviosidade expressiva ao longo do ano, sendo maio o mês de maior precipitação com uma média de $135 \mathrm{~mm}$. Tem uma pluviosidade média anual de $1136 \mathrm{~mm}$. De acordo com a classificação de Köppen e Geiger o clima da região é Af. A temperatura anual média do ar é de $23,0^{\circ} \mathrm{C}$. Seu clima tropical, quente e úmido pode favorecer o aparecimento de doenças, principalmente as provocadas por micro-organismos como fungos.

Foram realizadas visitas as comunidades para coleta das informações entre setembro e outubro de 2019 com o intuito de registrar as características dos sistemas de criação, do perfil dos criadores e das doenças que afetam as aves no local de estudo com aplicação de um questionário. Um total de 19 criadores foi entrevistado, sendo 15 da Comunidade da Baixa da Linha e quatro da Comunidade da Vila Guaxinim. A pesquisa foi aprovada pelo CEP/UFRB (Comitê de Ética em Pesquisa da Universidade Federal do Recôncavo da Bahia), cujo Número do Parecer é 3.597.888. Os dados obtidos foram avaliados utilizando-se o programa Microsoft Excel ${ }^{\circledR} 2010$, para os cálculos de médias, desvio padrão e determinação das percentagens.

\section{Resultados e discussão}

\section{Perfil dos criadores e descrição da atividade}

A análise dos dados revelou que $89,47 \%$ dos criadores de galinhas caipiras nas duas comunidades quilombolas visitadas são do sexo feminino, sendo que $42,11 \%$ apresentam idade variando entre $45-65$ anos. O tempo de exercício da atividade de criação de galinhas caipiras variou entre os entrevistados de 1 a 45 anos. A maioria dos avicultores $(63,15 \%)$ exerce esta atividade a mais de 10 anos (18 \pm 12 anos). $O$ plantel dos criadores de aves caipiras no local de estudo apresentou em média $30 \pm 12$ aves, com variação de 10 a 67 aves entres os criadores (Tabela 1).

A maior participação feminina na criação de aves nas comunidades estudadas (Tabela 1) corrobora 
os resultados relatados por Marcolino et al. (2009), pois, para estes autores, as mulheres são as principais gestoras da criação de aves caipiras e outros animais de pequeno porte. Este fato está associado ao grande conhecimento e busca de alternativas pelas mulheres para contribuir com o aumento da renda e segurança alimentar da família (Marcolino et al., 2009; Ramos,
2014). Além disso, considerando a cultura e as tradições que orientam a divisão do trabalho na agricultura familiar, a criação de animais de médio e pequeno porte, bem como as atividades produtivas desenvolvidas mais próximas das residências são geralmente atribuições das mulheres (Marcolino et al., 2009; Spanevello et al., 2019).

Tabela 1 - Registros do perfil dos criadores e descrição da atividade avícola em duas comunidades quilombolas do Recôncavo da Bahia. Breeder profile records and description of poultry activity in two quilombola communities of Recôncavo da Bahia.

\begin{tabular}{|c|c|c|c|c|c|}
\hline Criador & $\begin{array}{l}\text { Comunidade } \\
\text { quilombola }\end{array}$ & Sexo & $\begin{array}{l}\text { Idade } \\
\text { (anos) }\end{array}$ & $\begin{array}{l}\text { A quanto tempo desenvolve } \\
\text { a criação de aves (anos) }\end{array}$ & $\begin{array}{c}\text { № de aves na } \\
\text { criação } \\
\text { (unidades) }\end{array}$ \\
\hline 1 & Baixa da Linha & $\mathrm{F}$ & $45-65$ & 30 & 50 \\
\hline 2 & Baixa da Linha & $\mathrm{F}$ & $35-45$ & 10 & 15 \\
\hline 3 & Baixa da Linha & $\mathrm{F}$ & $18-35$ & 20 & 25 \\
\hline 4 & Baixa da Linha & $M$ & $>65$ & 45 & 40 \\
\hline 5 & Baixa da Linha & $M$ & $35-45$ & 6 & 40 \\
\hline 6 & Baixa da Linha & $\mathrm{F}$ & $45-65$ & 45 & 30 \\
\hline 7 & Baixa da Linha & $\mathrm{F}$ & $45-65$ & 45 & 10 \\
\hline 8 & Baixa da Linha & $\mathrm{F}$ & $45-65$ & 1 & 10 \\
\hline 9 & Baixa da Linha & $\mathrm{F}$ & $35-45$ & 1 & 20 \\
\hline 10 & Baixa da Linha & $\mathrm{F}$ & $35-45$ & 25 & 10 \\
\hline 11 & Baixa da Linha & $\mathrm{F}$ & $18-35$ & 6 & 30 \\
\hline 12 & Baixa da Linha & $\mathrm{F}$ & $45-65$ & 35 & 40 \\
\hline 13 & Baixa da Linha & $\mathrm{F}$ & $35-45$ & 20 & 30 \\
\hline 14 & Baixa da Linha & $\mathrm{F}$ & $18-35$ & 15 & 25 \\
\hline 15 & Baixa da Linha & $\mathrm{F}$ & $35-45$ & 10 & 12 \\
\hline 16 & Vila Guaxinim & $\mathrm{F}$ & $18-35$ & 3 & 30 \\
\hline 17 & Vila Guaxinim & $\mathrm{F}$ & $45-65$ & 4 & 30 \\
\hline 18 & Vila Guaxinim & $\mathrm{F}$ & $45-65$ & 12 & 67 \\
\hline 19 & Vila Guaxinim & $\mathrm{F}$ & $45-65$ & 18 & 50 \\
\hline
\end{tabular}

${ }^{\star} \mathrm{F}=$ feminino e $\mathrm{M}=$ masculino

Ao observar esses dados podemos também levantar a importância das mulheres na construção de sistemas produtivos mais sustentáveis baseados nos princípios da agroecologia, uma vez que elas participam de forma ativa na criação de galinhas que são animais que desempenham várias funções nos sistemas, como a produção de esterco, controle de insetos e plantas espontâneas, aumento da biodiversidade, além de ser fonte de alimentação para as famílias (Marcolino et al., 2009; Siliprandi, 2015).

Em contraste a elevada participação feminina na criação de aves caipiras nas comunidades estudadas verificou-se uma reduzida participação $(21,05 \%)$ de jovens (18-35 anos). O desinteresse dos jovens pelas atividades rurais em busca do futuro melhor no meio urbano vem sendo sinalizado a décadas por Abramovay et al., (1998). Dessa forma, é preciso estimular estes atores rurais, principalmente na agricultura familiar, como propagadores e multiplicadores dos saberes do campo.

Todos os entrevistados das comunidades quilombolas (100\%) criavam galinhas caipiras. Quando perguntado que tipos de aves além das galinhas caipiras criavam, $68,42 \%$ responderam que não criavam outras aves, e os demais criavam patos, pombos, galinha d'angola, gansos, raça índio gigante ou Brahma perdiz (galinha ornamental) (Figura 1). 


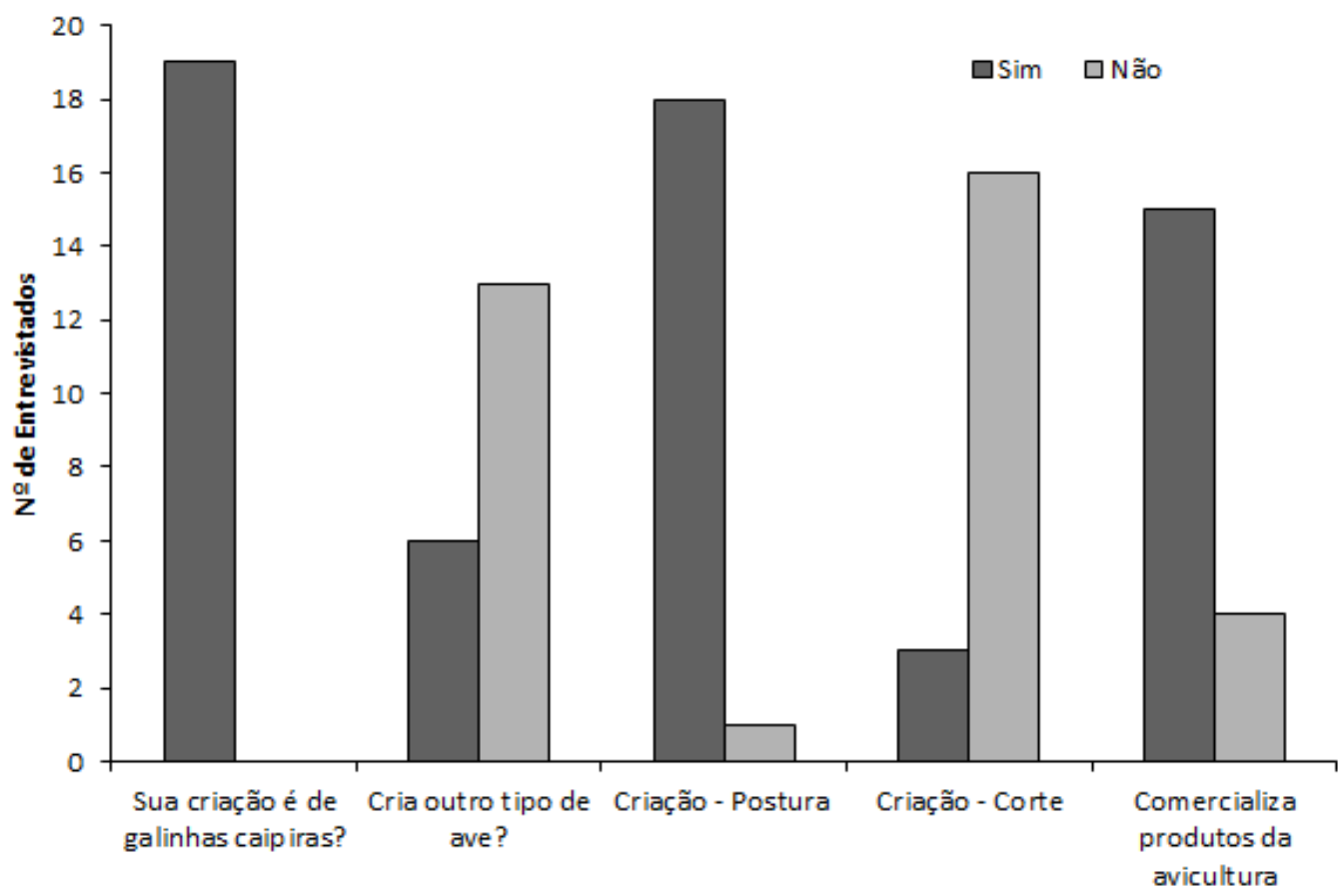

Figura 1 - Perfil da atividade de criação de galinha caipira em duas comunidades quilombolas do Recôncavo da Bahia. Cultivation activity profile of free-range chicken in two quilombola communities of the Recôncavo da Bahia.

As galinhas caipiras são comumente criadas soltas nos quintais, ciscando maior parte do tempo, em busca de insetos, minhocas, plantas e restos de alimentos (sistema extensivo) (Abou-Elezz et al., 2011). Estas aves se adaptam bem ao clima quente e são mais resistentes a algumas doenças, e o valor das aves quando comparado a outras é menor, sendo estas características atrativas para o produtor familiar (Embrapa, 2007; Abou-Elezz et al., 2011). Aves como peru e galinhas ornamentais e exóticas são mais caras e mais suscetíveis a doenças (Back, 2007; Vasconcelos et al., 2013). Este fato, possivelmente está relacio- nado à sua baixa frequência entre os criadores de galinhas caipiras nas comunidades quilombolas estudadas na região do Recôncavo da Bahia.

Entre os entrevistados $21,05 \%$ criavam aves caipiras apenas para subsistência (Figura 1). A maioria dos criadores $(78,95 \%)$ comercializam os produtos da avicultura (a venda é realizada para atravessadores), principalmente ovos e aves adultas (Figura 2). Segundo os entrevistados os pintinhos não são vendidos porque o retorno financeiro é maior quando se comercializa as aves adultas.

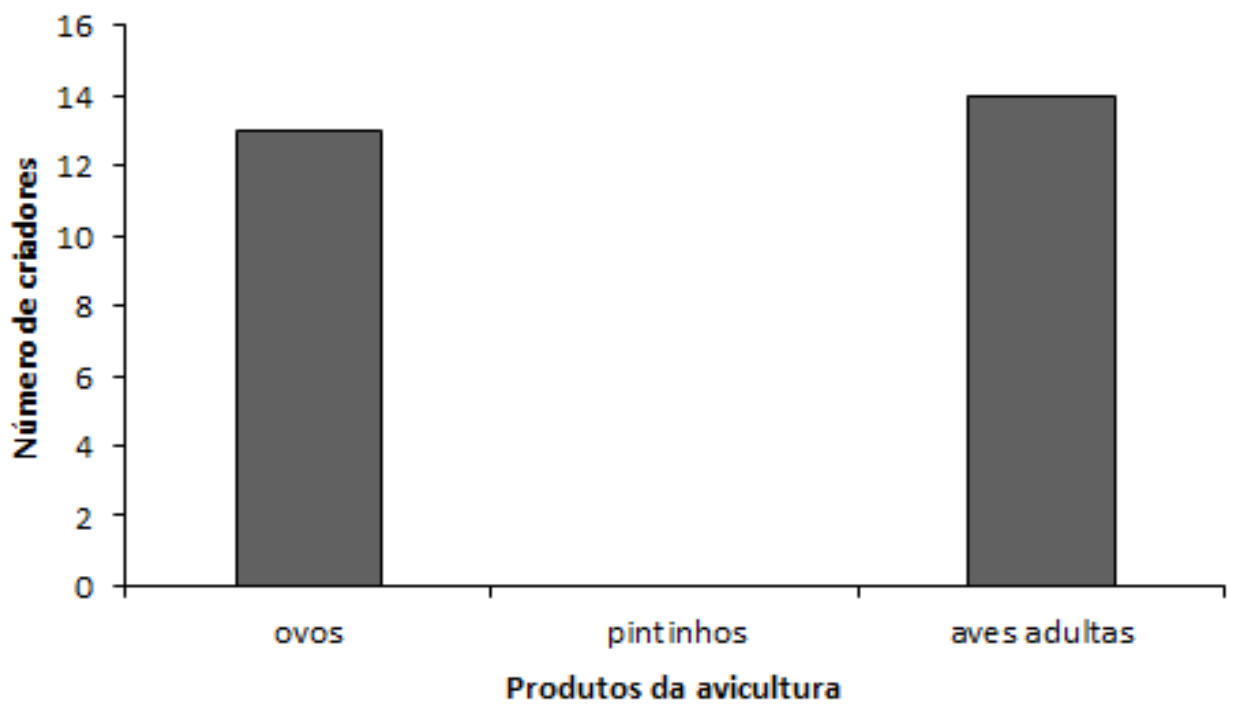

Figura 2 - Produtos comercializados pelos criadores de galinha caipira em duas comunidades quilombolas do Recôncavo da Bahia. Products marketed by free-range chicken farmers in two quilombola communities in the Recôncavo da Bahia. 


\section{Instalações das aves e Manejo alimentar}

No que se refere às instalações para criação das aves nas comunidades visitadas, $37 \%$ das criações são realizadas em galinheiros (abrigo coberto construído em alvenaria estrutural com bloco de cerâmica), sendo o sistema de criação semiextensivo (Figura 3).

O alojamento (instalações) das aves deve fornecer condições ideais para o crescimento e a produção de ovos, protegendo o plantel do vento, chuva e temperaturas extremas. Portanto, esses animais necessitam de ambiente e instalações confortáveis para que atinjam o potencial máximo em eficiência e produção. Assim, a escolha do local para a construção do galinheiro deve ser a primeira medida a ser considerada (Santos et al., 2009, Araújo, 2013; Goo et al., 2019). Dessa forma, o registro de criação das aves realizada com galinheiro pelos criadores familiares das comunidades quilombola avaliadas é um resultado positivo, uma vez que demonstra a preocupação dos criadores em disponibilizar um local mais adequado aos animais.

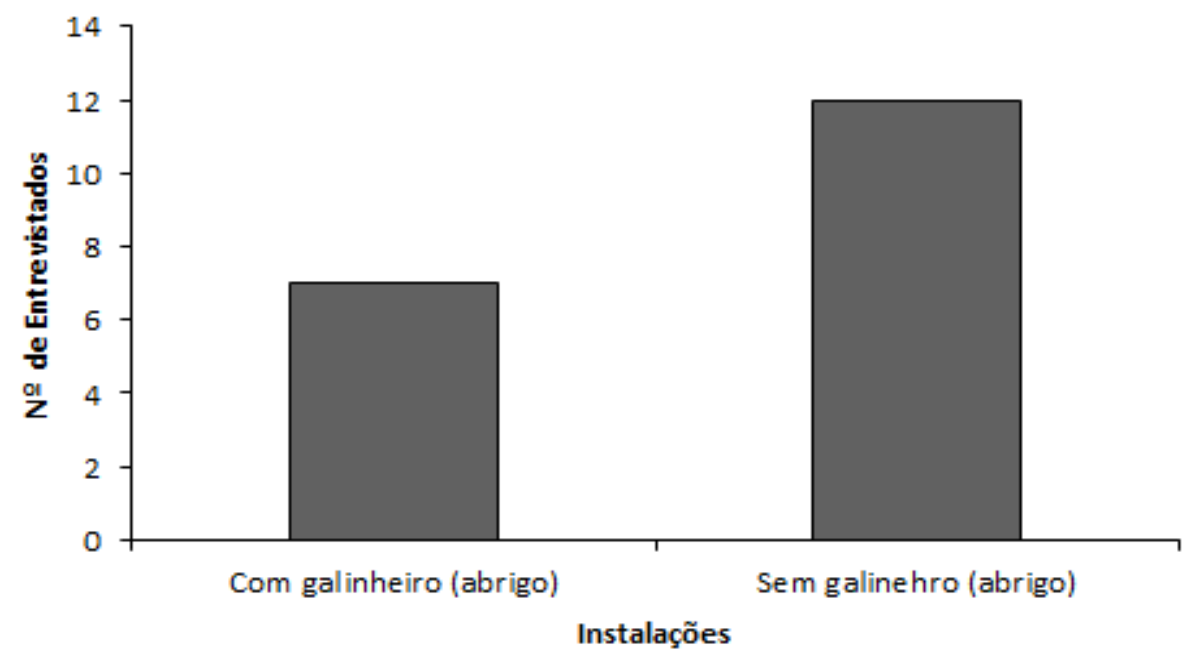

Figura 3 - Registro do número de criadores de galinha caipira que utilizam instalações (abrigo) em duas comunidades quilombolas do Recôncavo da Bahia. Record of the number of free-range hen farmers using facilities (shelter) in two quilombola communities in Recôncavo da Bahia.

A limpeza das instalações das criações das comunidades é basicamente a retiradas das fezes ou varrendo a mesma, apenas uma vez por dia (Tabela 2). Não foi registrado nenhum uso de produto químico ou natural para desinfestação das instalações. A limpeza das instalações também é necessária para promover um ambiente saudável para as aves e deve ser feita criteriosamente. Uma técnica utilizada para garantir a higiene das instalações é caiar as paredes do galinheiro com cal virgem (Araújo, 2013). Dessa forma, percebese a importância da assistência técnica em divulgar a importância da limpeza das instalações na sanidade dos animais e buscar junto aos criadores alternativas condizentes com a agricultura familiar para garantir a higiene do local e saúde dos animais.

Igualmente importante é o fornecimento de água limpa e adequada para as aves. As aves domésticas suportam ficar sem ração por um tempo, mas não sem água. A necessidade de água varia com a idade das aves, tipo de alimento, temperatura, entre outros fatores (Barbosa et al., 2014; James \& Frank, 2010). No presente estudo $26,32 \%$ dos criadores informaram cuidados em relação ao fornecimento de água limpa, a partir da troca periódica da água nos bebedouros (Tabela 2).

Para criação de aves deve ser atribuída à água a mesma importância a que se dá a outros fatores como instalações, alimentação e manejo, considerando que as aves de produção têm maior requerimento de água para seu desenvolvimento e bem estar (Barbosa et al., 2014). Além de necessária para fisiologia do animal a água é também um insumo relevante para o manejo da vacinação, limpeza, controle térmico do ambiente e desinfecção de equipamentos e instalações (Gama et al, 2008; Barbosa et al., 2014; Ferrari et al., 2016).

$\mathrm{Na}$ avicultura familiar a água também é utilizada como veículo para a administração de medicamentos alternativos, como o limão e o alho "machucado" que são colocados na água de bebida das aves para prevenir doenças (Viola et al., 2011; Molino et al., 2018).

Quando perguntado se forneciam ração para as aves $90 \%$ responderam que sim. O tipo de ração formulada industrial oferecido é variável como a ração de postura, engorda e crescimento, além do farelo de soja. No entanto, $78 \%$ destes criadores oferecem também alimento alternativo para suas aves como: milho, resto de comida, verduras, mandioca, jaca e aipim (Tabela 2). Esse resultado evidencia um pilar da produção agroecológica, que se refere a menor utilização de insumos externos a propriedade, propiciando a reciclagem de nutrientes (Teixeira et al., 2015). 
Tabela 2 - Descrição das atividades e manejo avícolas em duas comunidades quilombolas do Recôncavo da Bahia. Description of poultry activities and management in two quilombola communities of Recôncavo da Bahia.

\begin{tabular}{|c|c|c|c|c|}
\hline Criador & $\begin{array}{l}\text { Comunidade } \\
\text { quilombola }\end{array}$ & $\begin{array}{l}\text { Limpeza das } \\
\text { instalações* }\end{array}$ & $\begin{array}{l}\text { Fornecimento } \\
\text { de ração * }\end{array}$ & Tipo de ração utilizada \\
\hline 1 & Baixa da Linha & $\begin{array}{l}\text { Retira as fezes com } \\
\text { ancinho. } \\
\text { Troco água }\end{array}$ & $\operatorname{sim}$ & $\begin{array}{l}\text { Postura, engorda, crescimento, farelo, } \\
\text { milho, resto de verduras, jaca, mandioca } \\
\text { e aipim, }\end{array}$ \\
\hline 2 & Baixa da Linha & não & $\operatorname{sim}$ & Milho, farelo e resto de comida \\
\hline 3 & Baixa da Linha & Retira as fezes & $\operatorname{sim}$ & $\begin{array}{l}\text { Engorda, crescimento, milho e resto de } \\
\text { comida }\end{array}$ \\
\hline 4 & Baixa da Linha & não & $\operatorname{sim}$ & Milho, farelo e caroço \\
\hline 5 & Baixa da Linha & não & $\operatorname{sim}$ & Milho, farelo, resto de comida e verduras \\
\hline 6 & Baixa da Linha & não & $\operatorname{sim}$ & $\begin{array}{l}\text { rostura, engorda, crescimento, mino, } \\
\text { resto de comida e farelo, mandioca, } \\
\text { caroco e resto de verduras }\end{array}$ \\
\hline 7 & Baixa da Linha & não & $\operatorname{sim}$ & Milho, mandioca, farelo e resto de comida \\
\hline 8 & Baixa da Linha & não & $\operatorname{sim}$ & Postura, engorda, crescimento e milho \\
\hline 9 & Baixa da Linha & Varre, retira as fezes & $\operatorname{sim}$ & Crescimento e resto de comida \\
\hline 10 & Baixa da Linha & $\begin{array}{l}\text { Retira as fezes; troco a } \\
\text { água }\end{array}$ & $\operatorname{sim}$ & Milho, resto de comida e farelo \\
\hline 11 & Baixa da Linha & não & $\operatorname{sim}$ & Postura, engorda, crescimento e milho \\
\hline 12 & Baixa da Linha & não & $\operatorname{sim}$ & Milho, farelo, caroço e resto de comida \\
\hline 13 & Baixa da Linha & $\begin{array}{c}\text { Retira as fezes; troco a } \\
\text { água }\end{array}$ & $\operatorname{sim}$ & $\begin{array}{l}\text { Milho, farelo, resto de comida, resto de } \\
\text { verdura e jaca }\end{array}$ \\
\hline 14 & Baixa da Linha & não & $\operatorname{sim}$ & Milho e resto de comida \\
\hline 15 & Baixa da Linha & não & $\operatorname{sim}$ & Milho e resto de comida \\
\hline 16 & Vila Guaxinim & não & $\operatorname{sim}$ & Postura e milho \\
\hline 17 & Vila Guaxinim & $\begin{array}{c}\text { Retira as fezes; troco a } \\
\text { água }\end{array}$ & $\operatorname{sim}$ & Milho e resto de verdura \\
\hline 18 & Vila Guaxinim & $\begin{array}{c}\text { Retira as fezes; troco a } \\
\text { água }\end{array}$ & $\operatorname{sim}$ & Crescimento e milho \\
\hline 19 & Vila Guaxinim & não & sim & Crescimento, milho moído e milho inteiro \\
\hline
\end{tabular}

*Procedimento realizado apenas uma vez por dia.

Além dos cereais (milho e soja) que são utilizados em larga escala nas rações para monogástricos, outros alimentos podem ser utilizados desde que apresentem composição química e nutricional adequadas, assim como boa digestibilidade e proporcione boa absorção de nutrientes (Barbosa et al., 2007). A utilização de restos de culturas, como as raízes e as folhas de mandioca (Manihot esculenta Cranz) e batatadoce (Ipomoea batatas (L.) Lam.), bem como de frutos diversos e hortaliças são importantes componentes da dieta destes animais (Barbosa et al., 2007; Abou-Elezz et al., 2011).

A raspa da raiz da mandioca pode ser utilizada em formulações para dieta das aves com a finalidade de reduzir o emprego do milho e farelo de soja (rações industriais formuladas), pois esta é uma das opções de alimento alternativo energético e rico em amido (Nascimento et al., 2005; Rostagno et al., 2017).
Verifica-se que na alimentação dos animais são utilizados uma grande diversidade de ingredientes encontrados na propriedade que irão reduzir os custos com a alimentação dos animais, porém muitas vezes falta informações da forma correta de se utilizar e quais as proporções desses alimentos alternativos para garantir que as exigências dos animais estão sendo supridas contribuindo para a saúde do animal.

\section{Doenças relatadas pelos criadores de aves caipiras}

Os criadores relataram onze tipos de doenças que acometem as aves (carocha, cegueira, gôgo, febre, coriza, carocha nos olhos, carocha na "bunda" (ânus), rachadura nos pés, tristeza, verminose, virose e verruga). Verificou-se que para a maioria dos criadores (78,95\%) a doença mais frequente é o gôgo (coriza infecciosa). Apenas três criadores relataram não haver registrado em nenhum momento doenças nas aves (Figura 4). 


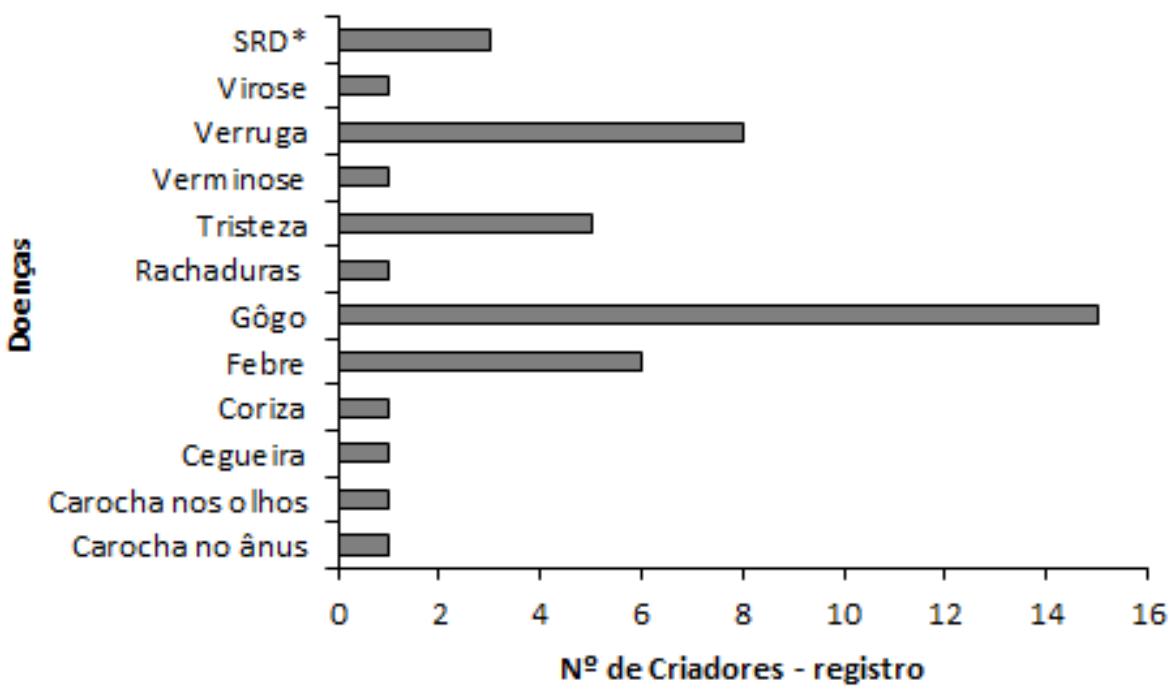

Figura 4 - Doenças relatadas por criadores de galinhas caipiras em duas comunidades quilombolas do Recôncavo da Bahia. * $\mathrm{SRD}=$ sem registro de doença. Diseases reported by free-range chicken farmers in two quilombola communities in the Recôncavo da Bahia. ${ }^{*} S R D=$ no disease record.

As doenças foram registradas conforme relato dos criadores, baseado nos sintomas observados pelos mesmos e no conhecimento que estes avicultores adquiriram ao longo dos anos em que exercem a atividade avícola. Dessa forma, em alguns casos observamos que o nome dado a doença é o próprio sintoma apresentado pela ave doente, como exemplo a tristeza e a febre relatada por muitos dos criadores entrevistados. Salientamos que para melhor descrição das doenças e controle da mesma a identificação desta enfermidade tem grande relevância.

$O$ gôgo dentre as enfermidades que podem ocorrer em criações de aves é a mais comum entre os produtores familiares, sendo esta doença associada especialmente ao manejo sanitário (Molino et al. 2018). Na produção em grande escala estes problemas são menores, pois maior atenção e investimento são dados às práticas de manejo sanitário.

\section{Medidas de controle de doenças adotadas}

Para pergunta referente a vacinação de aves, $73,68 \%$ dos criadores responderam que não vacinam suas aves, pois segundo os mesmos não tinham informações a este respeito (Figura 5). No entanto, a vacinação tem papel importante no controle e prevenção de enfermidades como a doenças de Newcastle (Canal \& Vaz, 2007; Canal \& Barbosa, 2009). Considerando que a vacinação é um instrumento com relevância para sanidade do plantel e em muitos casos de baixo custo na produção, sua adoção entre as medidas de controle de doenças é necessária (Canal \& Vaz, 2007). Vale ressaltar que existe vacina para a coriza infecciosa (gôgo), doença relatada pela maioria dos criadores.

O desconhecimento por parte dos avicultores da existência de vacinas para aves, indica a necessidade de investimento na transferência de informações para estes criadores, instruções referentes a melhor forma de utilização, bem como a articulação e parceria entre os membros da comunidade para aquisição e uso compartilhado destes medicamentos, visando assim diminuir os custos.

Observa-se na Figura 5 que $84,21 \%$ dos entrevistados responderam que as suas aves costumam ficar doentes. Quando as aves são acometidas por alguma enfermidade $57,90 \%$ dos criadores procuram assistência técnica para o tratamento da doença. Para adotar medidas de controle das enfermidades $52,63 \%$ recorrem a técnicos agropecuários e conhecimento popular (Figura 6). Segundo os entrevistados a comunidade possui um técnico agropecuário, além deste profissional os criadores recorrem aos profissionais de casas agropecuárias do município de Cruz das Almas-BA, sendo que não necessariamente este profissional é um técnico agropecuário.

Como forma de proteção das aves sadias quando são observados animais doentes $73,68 \%$ dos criadores separam estes animais (Figura 6), este procedimento é realizado para evitar a propagação da doença no plantel. $O$ isolamento dos animais doentes, pode não trazer benefício algum para o próprio doente, no entanto, esta é uma medida necessária para evitar ou reduzir propagação da doença (OPAS, 2010).

Os criadores de aves caipiras entrevistados adotam medidas preventivas para o controle de doenças das aves como a utilização de água com limão (Citrus limon L., Rutaceae) e alho amassado (Allium sativum L., Alliaceae), água com vinagre, cebola roxa picada (Allium cepa L., Alliaceae), folhas de melão de São Caetano (Momordica charantia L., Cucurbitaceae) são colocadas nos ninhos de postura e no local onde as galinhas chocam os ovos para repelir o piolho-degalinha (ácaro-de-galinha) (Figura 7). 


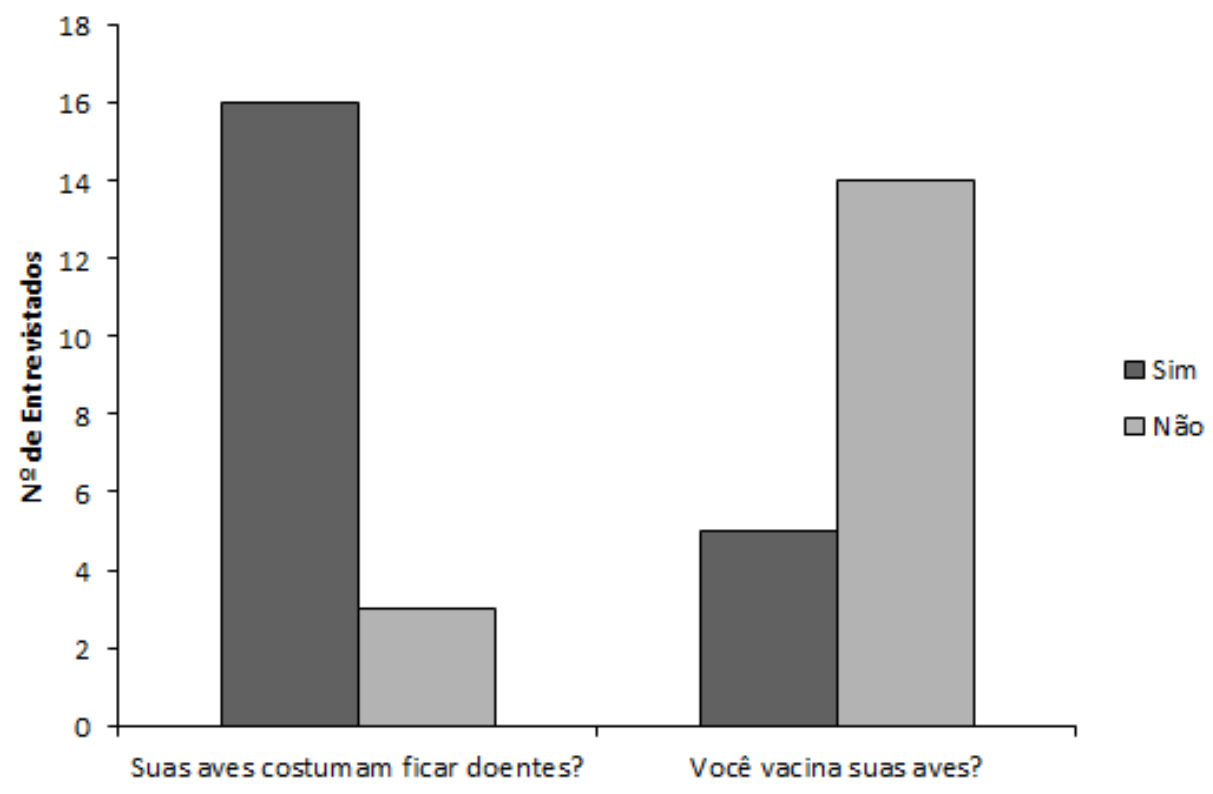

Figura 5 - Manejo da sanidade avícola adotado em duas comunidades quilombolas do Recôncavo da Bahia. Poultry health management adopted in two quilombola communities in Recôncavo da Bahia.

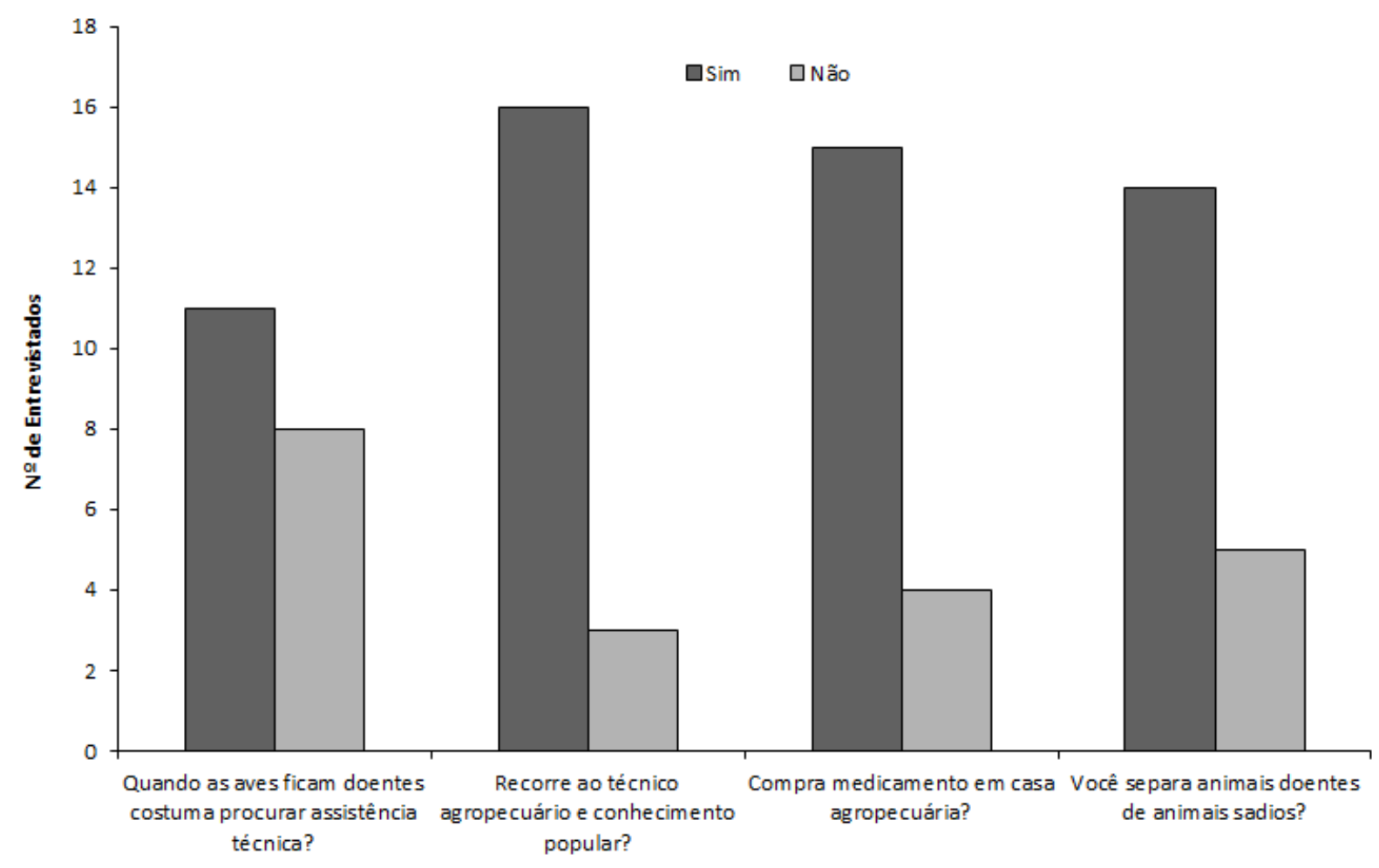

Figura 6 - Medidas de controle adotadas para prevenção e controle de doenças por criadores de galinhas caipiras em duas comunidades quilombolas do Recôncavo da Bahia. Control measures adopted for disease prevention and control by free-range chicken farmers in two quilombola communities in Recôncavo da Bahia.

Três produtores $(15,78 \%)$ responderam informando que compra medicamentos em casa agropecuária, como sanagogo, proverme, pó antipiolhos (para controle da pixilinga - Dermanyssus gallinae), mata bicheira ou lepecid para tratamento de machucados
(Figura 7). Outro criador relatou que usa o benzocreol para tratamento de indivíduos com sintomas de enfermidades do plantel. Apenas um dos entrevistados informou que não utilizar nenhum medicamento alternativo ou comercial. 


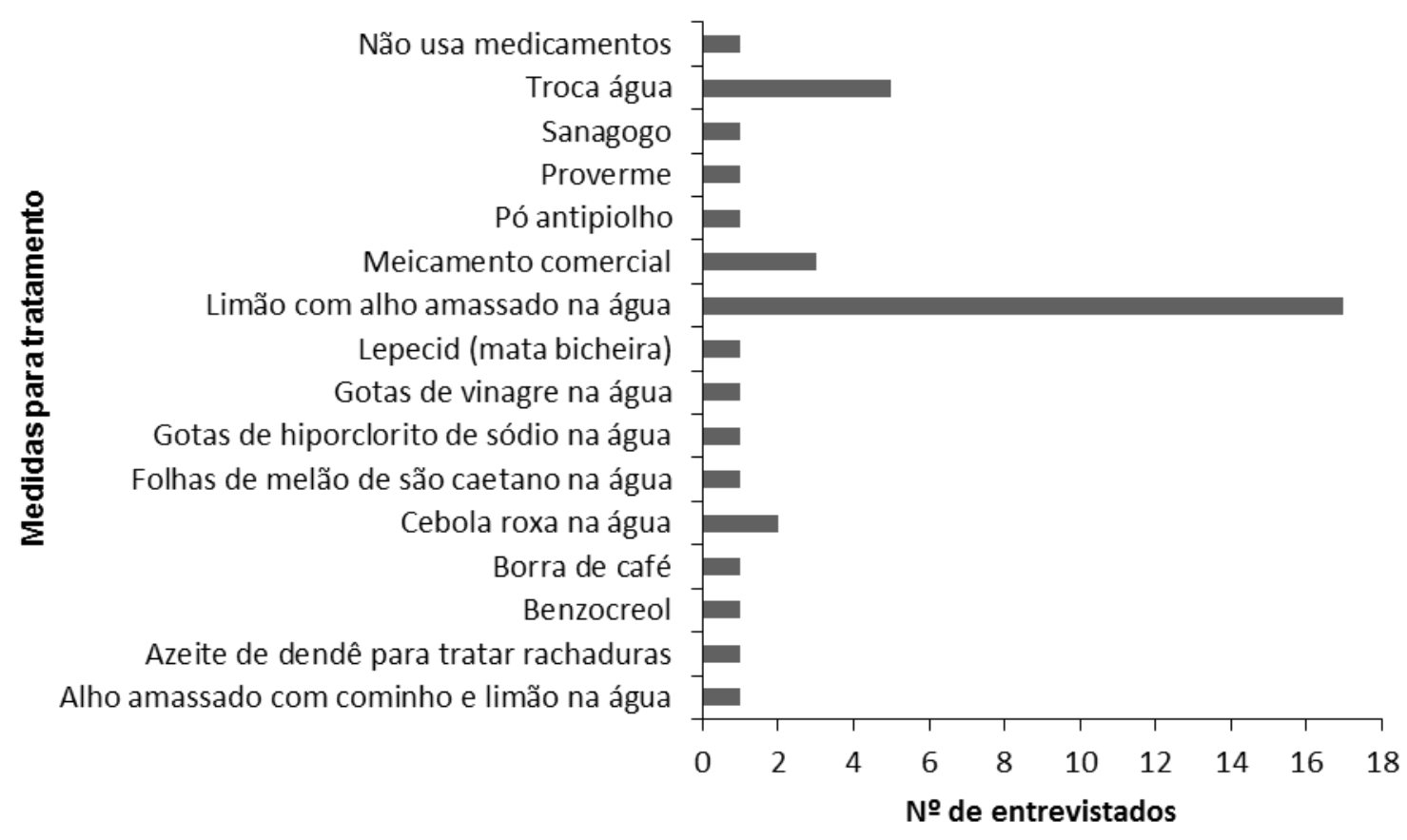

Figura 7 - Descrição das medidas alternativas e convencionais utilizadas para prevenção de doenças em galinhas caipiras de duas comunidades quilombolas do Recôncavo da Bahia. Description of alternative and conventional measures used for disease prevention in free-range chickens from two quilombola communities of Recôncavo da Bahia.

A maioria dos criadores das comunidades quilombolas avaliadas neste estudo utiliza medicamentos naturais para tratamento de suas aves (Figura 7). Este fato revela uma característica importante para manutenção do equilíbrio ecológico destes sistemas de criação animal. Sistemas agroecológicos de criação de aves caipira tem como premissa a substituição dos antibióticos por produtos naturais, fitoterápicos, pois estes são menos onerosos, resgata o conhecimento tradicional sobre saúde animal, passado de camponês a camponês ao longo do tempo (Marcolino et al., 2009; Royer et al., 2013).

De acordo com Molino et al. (2018) a utilização de remédios naturais como babosa, alho, limão, pinhãobravo, angico e cabeça-de-negro foram eficientes para o combate da coriza infecciosa (gôgo), sendo estas plantas medicinais potencias para uso como fitoterápicos no combate de febres, infecções e ferimentos. Chenopodium ambrosioides (erva-de-santa-maria) foi apontada como eficiente no controle de endoparasitos tanto na forma homeopática como fitoterápica por Vita et al. (2014).

\section{Conclusão}

A coriza infeciosa (gôgo) foi a doença relatada com maior frequência de ocorrência na criação de galinhas caipiras em comunidades quilombolas do Recôncavo da Bahia. O controle das doenças das aves nas comunidades é preventivo e na maioria dos casos as aves são tratadas com uso de medicamentos alternativos baseados no conhecimento popular.
O estudo revelou que a atividade avícola na área de estudo é exercida, principalmente por mulheres. A maior parte das criações é realizada para subsistência. No entanto, existe a comercialização de ovos e aves adultas para complementação da renda familiar.

\section{Referências}

Abou-Elezz FMK, Sarmiento-Franco L, Santos-Ricalde $R$, Solorio-Sanchez F (2011) Nutritional effects of dietary inclusion of Leucaena leucocephala and Moringa oleifera leaf meal on Rhode Island Red hens' performance. Cuban Journal of Agricultural Science 45(2):163-169.

Abramovay R, Silvestro $M$, Cortina N, Baldissera IT, Ferrari D, Testa VM (1998) Juventude e agricultura familiar: desafio dos novos padrões sucessórios. Brasília: UNESCO. 104p.

Albuquerque NI, Freitas CMKH, Sawaki H, Quanz D (1998) Manual sobre criação de galinha caipira na agricultura familiar: noções básicas. Belém: EmbrapaCPATU. 28p.

Alders RG, Dumas SE, Rukambile E, Magoke G, Maulaga W, Jong J, Costa R (2018) Family poultry: Multiple roles, systems, challenges, and options for sustainable contributions to household nutrition security through a planetary health lens. Maternal \& Child Nutrition 14(S3):1-14.

Araújo FG (2013) Bem estar e Ambiência das aves. Urutaí: IFGO. 99p. 
Back A (2007) Manejo sanitário de perus. Revista Brasileira de Reprodução Animal 31(3):322-327.

Barbosa FJV, Nascimento MPSB, Diniz FM, Nascimento HTS, Araújo Neto RB (2007) Sistema Alternativo de Criação de Galinhas Caipiras. Embrapa Meio-Norte, Sistemas de Produção. Disponível em: <https://sistemasdeproducao.cnptia.embrapa.br/FontesHTML/Ave/SistemaAlternativoCriacaoGalinhaCaipir a/Sanidade.htm> (Acesso em 30 mai 2019).

Barbosa FJV, Diniz FM, Clementino CS, Martins DM (2008) Sistema Alternativo de Criação de Aves Caipiras (SACAC): Núcleo de Multiplicação de Galinhas. Teresina: Embrapa Meio-Norte. 22p.

Barbosa TM, Silva FL, Rodriz CGQ, Oliveira RA, Navarro RD, Santana AP, Murata LS (2014) A importância da água na avicultura. Pubvet 8(19):1-22.

Canal CW, Barbosa TMC (2009) Enfermidade de Marek Complexo Leucótico Aviário e Reticuloendoteliose In: Júnior AB, Silva EN, Fábio J, Sesti L, Zuanaze MAF. Doenças das aves. 2.e. Campinas: FACTA. p.569-576.

Canal CW, Vaz CSL (2007) Vacinas víricas. In: Flores EF. Virologia Veterinária. 1.ed. Santa Maria: UFSM. p.329-354.

Cruz FGG, Chagas EOC, Botelho TRP (2013) Avicultura familiar como alternativa de desenvolvimento sustentável em comunidades ribeirinhas do Amazonas. Interações 14(2):197-202.

Delgado GC, Bergamasco SMPP (2017) Agricultura familiar brasileira: desafios e perspectivas de futuro. Brasília: Ministério do Desenvolvimento Agrário. 470p.

Embrapa - Empresa Brasileira de Pesquisa Agropecuária (2007) Criação de galinhas caipiras. Brasília: Embrapa Informação Tecnológica. 73p. (ABC da Agricultura Familiar, 20).

FAO (2014) Family poultry development - Issues, opportunities and constraints. Animal Production and Health Working Paper. n.12. Rome.

Ferrari G, Paton D, Duffy S, Bartels C, Knight-Jones T (2016) Foot and mouth disease vaccination and postvaccination monitoring. $\mathrm{FAO} / \mathrm{Food}$ and Agriculture Organization of the United Nations and World Organisation for Animal Health. 74p.

Goo D, Kim JH, Park GH, Delos Reyes JB, Kil DY (2019) Effect of heat stress and stocking density on growth performance, breast meat quality, and intestinal barrier function in broiler chickens. Animals 9(107):2-10.
Heck FM (2016) Transformações técnicas na avicultura e os sujeitos sociais no território. Revista NERA 19(33):98-118.

James RG, Frank BF (2010) Modern Livestock and poultry production. Clifton Park: Cengage Learning. $693 p$.

Machado CFD (2016) Estratégias socioeconômicas da comunidade quilombola de Júlio Borges frente ao cenário do desenvolvimento agrário da região do Alto Jacuí/RS. UniCRuz (Tese de Mestrado em Práticas Socioculturais e Desenvolvimento Social).

Machado CFD, Mera CMP (2016) A comunidade quilombola como espaço de inclusão social: o caso de Júlio Borges. In: Brutti TA, Peranzoni VC, Adams A (ed) Inclusão Social e preconceitos na contemporaneidade. 3ed, Curitiba. p.50-75.

Marcolino A, Vieira A, Nunes E, Xenofonte GHS, Porto I, Souza LA, Moura M, Patricia M (2009) Agroecologia e criação de galinhas capoeira. In: Caatinga. Sertão que dá certo $n^{0}$ 3. Ouricuri: Caatinga. 40p.

Molino JP, Silva FMA, Silva FB, Araújo CA, Guerra JLRM (2018) Alternativas de controle do "gogo" (coriza infecciosa) em galinhas caipiras no alto sertão de Alagoas. Cadernos de Agroecologia 13(1):1-7.

Nascimento GAJ, Costa FGP, Júnior V SA, Barros LR (2005) Efeitos da substituição do milho pela raspa de mandioca na alimentação de frangos de corte, durante as fases de engorda e final. Ciência Agrotécnica 29(1):200-207.

Nogueira CM, Jesus, E (2013) A pequena produção avícola familiar e o Sistema de Integração no oeste catarinense: "uma prisão de portas abertas". Caderno $\mathrm{CRH}, 26(67): 123-138$.

OPAS - Organização Pan-Americana da Saúde (2010). Módulos de princípios de epidemiologia para o controle de enfermidades. Módulo 6: controle de enfermidades na população. Brasília: OPAS/MS. 38p.

Poultryhub. (2019) Health management. Disponível em: http://www.poultryhub.org/health/health-management/ (Acesso em 20 set. 2019).

Quinzeiro Neto T, Beserra Júnior JS, Costa JB, Pinho AKS, Santos JJRS, Brasil EP, Santos Junior JB (2017) Manual do Sistema de Produção Sustentável de Galinhas Caipiras - (Procap): Orientações básicas para a construção de galinheiros, manejo sustentável e equipamentos. Brasília: EMBRAPA. 82p.

Ramos CP (2014) Mulheres rurais atuando no fortalecimento da agricultura familiar local. Gênero 15(1): $29-46$. 
Rennó PP, Queiroz FM, Garcia BP, Prado RNA, Simões MM, Souza JPF, Almeida MV, Souza MG, Bassan LM, Pereira REP (2008) Endoparasitose em aves - revisão de literatura. Revista Científica Eletrônica de Medicina Veterinária 1(11):1-6.

Rostagno HS, Albino LAT, Donzelle JL, Gomes PC, Oliveira RF, Lopes DC, Ferreira AS, Barreto SLT (2017) Tabelas brasileiras para aves e suínos: composição de alimentos e exigências nutricionais. 4. ed. Viçosa: UFV. $488 p$.

Royer AFB, Garcia RG, Borille R, Santana MR, Nunes KC (2013) Fitoterapia aplicada a avicultura industrial. Enciclopédia Biosfera 9(17):1466-1484.

Sales MNG (2015) Estratégias de criação de galinhas caipiras para geração de estercos limpos para a olericultura orgânica. Disponível em: $<$ https://biblioteca.incaper.es.gov.br/digital/bitstream/ite $\mathrm{m} / 752 / 1 /$ estrategiasdecriacaodegalinhascaipirasparageracaoNeves.pdf> (Acesso em 15 set 2019).

Sankhyan V, Katoch S, Thakur YP, Dinesh K, Patial S, Bhardwaj $N$ (2013) Analysis of characteristics and improvement strategies of rural poultry farming in north western Himalayan state of Himachal Pradesh, India. Livestock Research for Rural Development 25(211):1-8.

Santos KMP, Garavello MEPE (2016) O caso dos agricultores quilombolas da Reserva de Desenvolvimento Sustentável Quilombos Barra do Turvo, SP. REDES: Revista do Desenvolvimento Regional 21(3):196-216.

Santos MW, Ribeiro AGP, Carvalho LS (2009) Criação de galinha caipira para produção de ovos em regime semiintensivo. Niterói: Programa Rio Rural. 30p.
Siliprandi E (2015) Mulheres e Agroecologia: Transformando o campo, as florestas, as pessoas. Rio de Janeiro: UFRJ. 356p.

Schmidt NS, Silva CL (2018) Pesquisa e Desenvolvimento na Cadeia Produtiva de Frangos de Corte no Brasil. Revista de Economia e Sociologia Rural 56(3):467-482.

Spanevello RM, Doege AMN, Drebes LM, Lago A (2019) Mulheres rurais e atividades não agrícolas no âmbito da agricultura familiar. Revista Desenvolvimento em Questão 16(45): 250-265.

Teixeira GGM, Miranda DR, Teles NC, Santos MAP, Simonetti ERS (2015) Extensão rural e agroecologia: qualificação técnica de produtores rurais. Cadernos de Agroecologia 10(3):1-5.

Van Eekeren N, Maas A, Saatkamp HW, Verschuur M (2006) Criação de galinhas em pequena escala. Agrodok 4. Wageningen: Fundação Agromisa. 100p.

Vasconcelos TCB, Nogueira DM, Pereira VLA, Nascimento ER, Bruno SF (2013) Chlamydophila psittaci em aves silvestres e exóticas: uma revisão com ênfase em saúde pública. Enciclopédia Biosfera 9(16):1-16.

Viola ES, Viola TH, Lima GJMM, Avila VS (2011) Água na avicultura: importância, qualidade e exigências. In: EMBRAPA. (ed.). Manejo Ambiental na Avicultura, cap.2, p.35-123.

Vita GF, Ferreira I, Pereira MAV, Costa AR, Sanavria A, Barbosa CG, GSM, Vasconcellos, HVG (2014) Eficácia de Chenopodium ambrosioides (erva-de-santa-maria) no controle de endoparasitos de Gallus gallus (galinha caipira). Pesquisa Veterinária Brasileira 34(1):39-45. 